\title{
Acute portal vein thrombosis leading to small bowel stricture
}

\author{
B.K.S. Bulathsinhala, R.C. Siriwardana, C.A.H. Liyanage \\ North Colombo Teaching Hospital, Ragama, Sri Lanka.
}

Key words: Portal vein thrombosis; small bowel stricture; small bowel resection

\section{Introduction}

A 38 year old patient with a family history of thrombotic disease presented with sudden onset diffuse abdominal pain and derangement of liver functions. On imaging there was thrombosis of the main truck of the portal vein with oedema of the proximal jejunum. The episode was managed with anticoagulants. Two months after he presented again with bilious vomiting after meals. Barium meal and follow through revealed an obstruction at the proximal jejunum. This part was resected and primarily anastomosed.

\section{Case presentation}

A 38 year old male presented to the emergency department with sudden onset diffuse abdominal pain and deterioration of liver functions. He had strong family history of thrombotic disease. Computed tomogram (CT) and portal venous angiogram revealed acute portal vein thrombosis (PVT). There was oedema of proximal small bowel loops (figure 1). The acute episode was managed conservatively. He was started on low molecular weight heparin and warfarin. During follow-up visits his liver functions improved and there were no oesophageal varices. He was referred to the haematologist and the family members were encouraged for thrombophilia screening. No definite thrombotic disease was found following extensive screening.

Two months after the acute attack, he presented with progressive bilious vomiting after meals. The upper gastric endoscopy was normal up to the third part of the duodenum. The patient underwent barium meal and follow through. There was a stricture at proximal jejunum $20 \mathrm{~cm}$ from the duodenojejunal flexure (figure1). Upper jejunal stricture was noted during the laparotomy. There were no adhesions, bands, ongoing intra-abdominal inflammatory process or evidence of previous sepsis. Stricture was resected and anastomosed.

Correspondence: B.K.S.Bulathsinhala

E-mail: sandunbulathsinhala82@gmail.com

Received: 10-05-2017 Accepted: 20-10-2017

(iD) http://orcid.org/0000-0002-9915-4071

DOI: http://doi.org/10.4038/sljs.v35i3.8415
Patient made an uneventful recovery. Patient was started on life-long anticoagulation. Histology revealed $10 \mathrm{~cm}$ trans mural fibrosis of small bowel without any other pathology in the normal mucosa. The Follow-up abdominal CT after 3 months showed extensive collaterals around the portal vein and flow in superior mesenteric vein.

\section{Discussion and conclusion}

Acute portal vein thrombosis is known complication seen in patients with thrombotic disease [1]. The question of starting anticoagulation is a crucial decision. With anticoagulants, recanalization rates close to $80 \%$ has been reported $[2,3]$. However thrombolytic therapy should be reserved for patients with severe disease and are associated with severe complications including bleeding [4]. Rate of spontaneous recanalization is not well documented. Acute ischemia caused by PVT can lead to congestion and bowel infraction. In most cases this does not happen because of the collateral venous drainage [5]. However collaterals may not be adequate rarely leading to late ischemic strictures. Few similar cases have been reported in the literature [6]. This rare complication needs to be considered in patients complaining of intestinal symptoms after acute PVT.

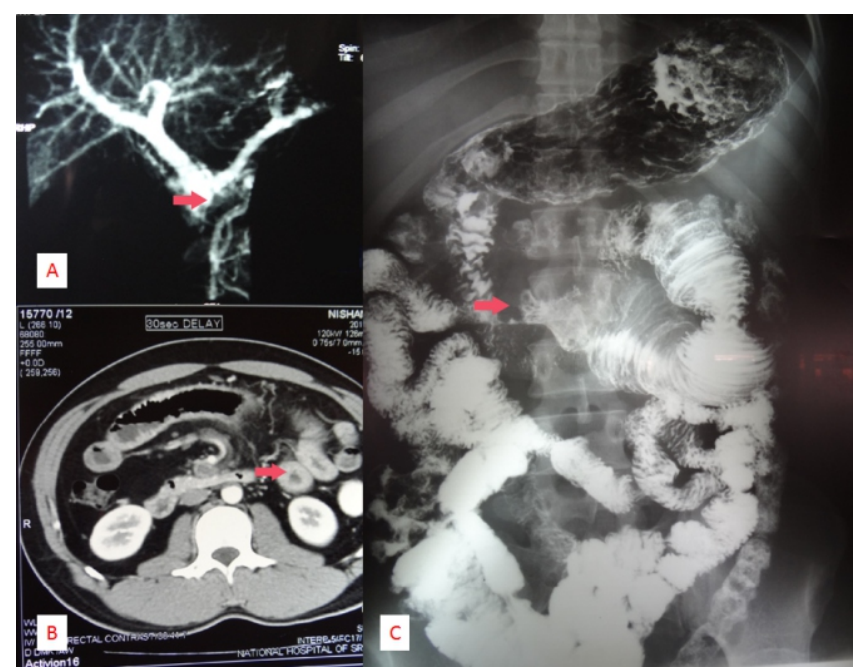

Figure 1. A - Thrombosed main portal vein,

B - Computed Tomogram $\backslash$ showing oedema of proximal small bowel loops,

C- Barium meal showing stricture at proximal jejunum. 


\section{References}

1. Shibahara K, Tatsuta K, Orita H, Yonemura T, Kohno H. Superior Mesenteric and Portal Vein Thrombosis Caused by Congenital Antithrombin III Deficiency: Report of a Case. Surg Today. 2007 2007/04/01;37(4):308-10.

DOI: doi.org/10.1007/s00595-006-3382-7

2. Sheen CL, Lamparelli H, Milne A, Green I, Ramage JK. Clinical features, diagnosis and outcome of acute portal vein thrombosis. QJM. 2000 August 1, 2000;93(8):531-4. DOI : doi.org/10.1093/qjmed/93.8.531

3. Plessier A, Darwish-Murad S, Hernandez-Guerra M, Consigny Y, Fabris F, Trebicka J, et al. Acute portal vein thrombosis unrelated to cirrhosis: A prospective multicenter follow-up study. Hepatology. 2010;51(1):210-8.

DOI:doi.org/10.1002/hep.23259
4. Chawla Y, Duseja A, Dhiman RK. Review article: The modern management of portal vein thrombosis. Vol. 30, Alimentary Pharmacology and Therapeutics. 2009. p. 881-94. DOI: doi.org/10.1111/j.1365-2036.2009.04116.x

5. Kim JY HH, Byun JY. Intestinal infarction secondary to mesenteric venous thrombosis CT - pathological correlation.J Comput Assist Tomogr. 1993;17:382-5.

DOI: doi.org/10.1097/00004728-199305000-00008

6. Antoch G HO, Pourhassan S, Stock W. Ischaemic jejunal stenosis complicating portal and mesenteric vein thrombosis: a report of two cases. Eur J Gastroenterol Hepato. 2001 Jun;13(6):707-10. DOI: doi.org/10.1097/00042737-200106000-00015

\section{Learning Points:}

- Patient with a history of portal vein thrombosis presenting with upper gastrointestinal symptoms should be further investigated to exclude small bowel obstruction.

- Other causes for bowel obstructions should be carefully ruled out on preoperative evaluation and during surgery.

- Early systemic anticoagulation during acute episode of PVT reduces the devastating complications like bowel necrosis while enhancing recanalization. 